\title{
Violent Video Games Stress People Out and Make Them More Aggressive
}

\author{
Youssef Hasan $^{1 *}$, Laurent Bègue ${ }^{1}$, and Brad J. Bushman ${ }^{2,3}$ \\ ${ }^{1}$ University Pierre Mendès-France, Grenoble, France \\ ${ }^{2}$ The Ohio State University, Columbus, Ohio \\ ${ }^{3}$ VU University, Amsterdam, the Netherlands
}

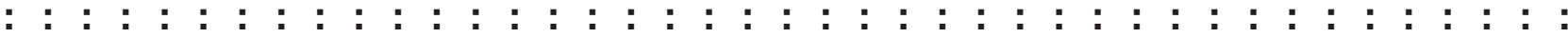

It is well known that violent video games increase aggression, and that stress increases aggression. Many violent video games can be stressful because enemies are trying to kill players. The present study investigates whether violent games increase aggression by inducing stress in players. Stress was measured using cardiac coherence, defined as the synchronization of the rhythm of breathing to the rhythm of the heart. We predicted that cardiac coherence would mediate the link between exposure to violent video games and subsequent aggression. Specifically, we predicted that playing a violent video game would decrease cardiac coherence, and that cardiac coherence, in turn, would correlate negatively with aggression. Participants $(N=77)$ played a violent or nonviolent video game for $20 \mathrm{~min}$. Cardiac coherence was measured before and during game play. After game play, participants had the opportunity to blast a confederate with loud noise through headphones during a reaction time task. The intensity and duration of noise blasts given to the confederate was used to measure aggression. As expected, violent video game players had lower cardiac coherence levels and higher aggression levels than did nonviolent game players. Cardiac coherence, in turn, was negatively related to aggression. This research offers another possible reason why violent games can increase aggression-by inducing stress. Cardiac coherence can be a useful tool to measure stress induced by violent video games. Cardiac coherence has several desirable methodological features as well: it is noninvasive, stable against environmental disturbances, relatively inexpensive, not subject to demand characteristics, and

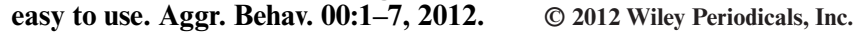

Keywords: violent video games; aggression; cardiac coherence

\section{INTRODUCTION}

\author{
"Stress is an ignorant state. It believes that everything is an \\ emergency." \\ -Natalie Golberg, American author
}

In emergency situations, the body responds with stress. Stress is an undesirable state because it can have harmful effects on the body, such as cardiovascular disease (Weiten, Dunn, \& Hammer, 2011). Most people already experience enough stress in their lives without intentionally exposing themselves to more stress. We argue that violent video game players do just that - they intentionally expose players to stressful situations in which enemies are trying to kill them. Although some video games can have a relaxing effect on players (Russoniello, O'Brien, \& Parks, 2009; Whitaker \& Bushman, 2012), violent video games have the opposite effect. Research has shown that violent video games increases physiological arousal, such as heart rate (Barlett \& Rodeheffer,
2009), blood pressure and skin conductance (Arriaga, Esteves, Carneiro, \& Monteiro, 2006), and stress hormones such as epinephrine and nor-epinephrine (Lynch, 1999). Although nobody actually dies, violent players may still experience stress.

It is well known that violent video games increase aggression (see Anderson et al., 2010 for a metaanalytic review). It is also well known that that stressful situations such as crowding, unpredictable noise, unpleasant odors, and hot temperatures increase aggression (see Bushman \& Huesmann, 2010 for a review). The present research links these two well-established empirical findings by investigating increased stress as one possible explanation of why

\footnotetext{
*Correspondence to: Youssef Hasan, LIP, University of Grenoble, France, 1251, Av. Centrale, BP47, 38040 Grenoble, France. E-mail: Youssef.Hasan@upmf-grenoble.fr
}

Received 4 February 2012; Accepted 6 September 2012

Published online in Wiley Online Library (wileyonlinelibrary.com). DOI: $10.1002 / a b .21454$ 
violent video games increase aggression. Rather than relying on self-report measures of stress that may be subject to demand characteristics and other biases (e.g., Nisbett \& Wilson, 1977), we examine for the first time cardiac coherence as a possible mediator of the link between exposure to violent video games and subsequent aggression. We chose to focus on cardiac coherence because it is an excellent measure of reduced stress.

\section{Cardiac Coherence}

Heart rate is affected by the autonomic nervous system (Acharya, Joseph, Kannathal, Lim, \& Suri, 2006; Fraser \& Swinney, 1986; Kleiger et al., 1991). The autonomic nervous system is divided into two opposing subsystems: the sympathetic nervous system and the parasympathetic nervous system. The sympathetic nervous system works like an accelerator on the heart - it increases heart rate to mobilize the body in response to stress, called a fight-flight response. In contrast, the parasympathetic nervous system works like a brake on the heart - it promotes maintenance of the body at rest by controlling most of the body's internal organs. Imbalance in the autonomic nervous system occurs when people experience negative emotions (Childre \& Cryer, 2004).

Breathing influences the way the autonomic nervous system regulates heart rate. Inhalation inhibits the parasympathetic system and increases heart rate, whereas exhalation stimulates the parasympathetic system and decreases heart rate. This rhythmic shift in heart rate associated with respiration is known as respiratory sinus arrhythmia (Berntson, Casioppo, \& Quigley, 1993; Chess, Tam, \& Calaresu, 1975).

Heart rate variability is the amount heart rate fluctuates, as measured by the variation in the beat-tobeat interval. Heart rate variability is an indicator of greater autonomic nervous system balance (Lehrer, Woolfolk, \& Sime, 2007), and reflects the influence of the autonomic nervous system on how hard the heart works (Miličević, 2005). Heart rate variability was first used clinically in 1965 when doctors noted that fetal distress was preceded by changes in interbeat intervals before any appreciable change occurred in the heart rate itself (Hon \& Lee, 1965).

Directly relevant to the present study is a large body of research showing a link between lower heart rate variability and negative emotions such as anger (Acharya et al., 2006; Carney \& Rich, 1988; Fraser \& Swinney, 1986; Kleiger et al., 1991; McCraty, Atkinson, Tiller, Rein, \& Watkins, 1995; Miličević, 2005). Research also shows a link between lower rate variability and antisocial behavior, such as aggression (Lahey, Hart, Pliszka, Applegate, \& McBurnett, 1993;
Scarpa \& Haden, 2006; Scarpa, Tanaka, \& Haden, 2008; Susman \& Pajer, 2004). Likewise, reduced respiratory sinus arrhythmia is linked to antisocial behavior (Mezzacappa et al., 1997). Although previous research has linked exposure to violence to increased heart rate and faster respiration (Fourie, 2008), the link between exposure to violence and lower heart rate variability remains unclear. Generally, there are no gender differences in heart rate variability (Acton, 2011; Ramaekers, Ector, Aubert, Rubens, \& Van de Werf, 1998).

Research has shown that breathing can increase heart rate variability and respiratory sinus arrhythmia, resulting in a balance of sympathetic and parasympathetic activity that reduces stress and provides greater relaxation and feelings of well being (Bolis, Licinio, \& Govoni, 2002). Cardiac coherence is defined as the synchronization of the rhythm of breathing to the rhythm of the heart (Carney \& Rich, 1988; McCraty et al., 1995). It is reflected by a sine wave-like pattern in the heart rhythms consisting of a smooth repetitive oscillation. One component of this pattern is frequency, which determines how many oscillations occur within a unit time interval. At a frequency of about 0.1 hertz, the oscillation in heart rate between exhalation and inhalation tends to be maximal (Vaschillo, Lehrer, Rishe, \& Konstantinov, 2002). This usually occurs at about six breaths per minute. Cardiac coherence is a state in which heart rate variability is highly regular (Church, 2007). Although heart rate variability is defined as beat-to-beat changes in heart rate, cardiac coherence is defined as the smoothness or synchronization of these changes as they are influenced by the automatic nervous system (Childre \& Cryer, 2004).

Cardiac coherence is a relatively new measure of autonomic nervous system balance (Tiller, McCraty, \& Atkinson, 1996). When cardiac coherence occurs, the frontal, temporal, and parietal-occipital regions of the brain are activated; the autonomic nervous system is balanced; and the body functions with increased harmony and efficiency (Carney \& Rich, 1988; Childre \& Cryer, 2004; McCraty et al., 1995), such as in the circulatory and nervous systems (McCraty \& Tomasino, 2006).

Previous research has shown when people experience positive emotions such as appreciation, joy, gratitude, and love, fluctuations in heart rate variability are small and cardiac coherence occurs (Childre \& Cryer, 2004; Church, 2007; Fig. 1A). Previous research has shown that cardiac coherence is associated with decreased anxiety and depression, decreased physical symptoms related to stress, increased immune functions, decreased cortisol 

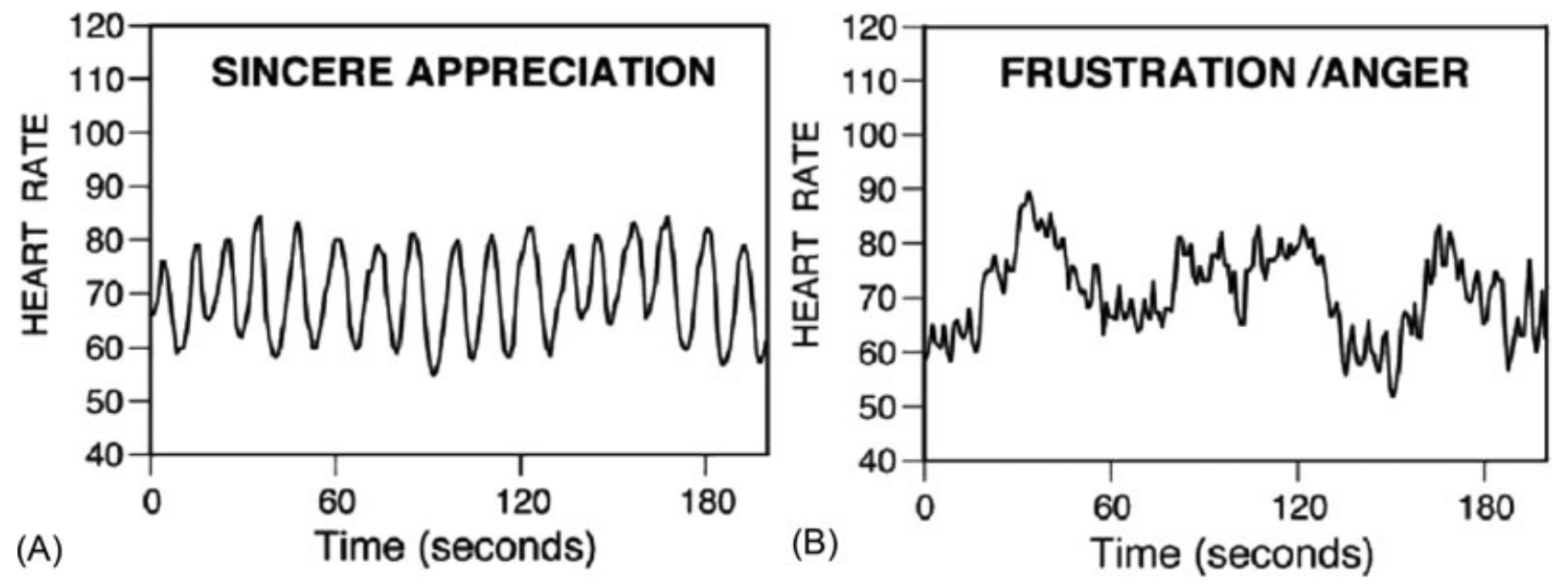

Fig. 1. (A) Cardiac variability over time in response to positive emotions. (B) Cardiac variability over time in response to negative emotions. From McCraty (2002).

production (a stress hormone), and increased DHEA (Dehydroepiandrosterone) define as the antistress hormone that keeps in check and corrects blood cortisol levels (Mikulka, 2011; Wickens, 2009). Biofeedback programs designed to reduce stress often use breathing and relaxation techniques to achieve a state of cardiac coherence (Maria, 2009; Nunan et al., 2009). In contrast, when people experience negative emotions such as stress, anger, frustration, sadness, and anxiety, fluctuations in heart rate variability are large and cardiac coherence decreases (Childre \& Cryer, 2004; Church, 2007; Fig. 1B), a state called cardiac incoherence. When people feel negative emotions, cardiac incoherence signals the brain, impedes thinking, and hinders decision-making (Feinstein, 2006).

Cardiac coherence also has at least six other attributes that are desirable to researchers studying video game effects. First, cardiac coherence is more directly related to negative affect such as stress than other physiological measures (Childre \& Cryer, 2004; McCraty \& Tomasino, 2006) because it can distinguish sympathetic from parasympathetic regulation of the heart rate (Tiller et al., 1996). Second, cardiac coherence is less invasive than other physiological measures such as skin conductance, blood pressure, and heart rate (e.g., it is difficult to play a video game with finger clips or arm cuffs). Cardiac coherence is measured using a comfortable clip that attaches to the earlobe. Measures of heart rate, blood pressure, and skin conductance use pressurized cuffs or sensors on either the upper arm or the finger. These often draw attention and can even be painful (especially the blood pressure cuff), which can elicit emotional reac- tions (Kahneman, Diener, \& Schwarz, 2003). Third, cardiac coherence is generally stable against various forms of environmental disturbance, such as muscle movements that often occur when playing video games. Fourth, cardiac coherence is less subject to demand characteristics than self-report measures of stress. Fifth, cardiac coherence equipment is relatively inexpensive in comparison to other physiological equipment. Sixth, cardiac coherence measures are very easy for researchers to use.

\section{Present Research}

In the present study, participants were randomly assigned to play either a violent or nonviolent video game while their cardiac coherence was measured. Next, they competed against an ostensible partner on a task in which the winner could blast the loser with loud noise through headphones. The intensity and duration of noise participants gave their ostensible partner was used to measure aggressive behavior. We predicted that participants who played a violent game would have lower cardiac coherence than participants who played a nonviolent game, and that cardiac coherence, in turn, would be negatively related to aggression.

\section{METHOD}

\section{Participants}

Participants were 77 French university students ( $83 \%$ female; $M_{\text {age }}=20.1, S D=3.1 ; 100 \%$ Caucasian $)$ who received course credit. 


\section{Procedure}

Participants were told that the researchers were studying the effects of the brightness of video games on visual perception and physiological arousal. They were asked if they had any vision problems or cardiovascular disease; none did. After informed consent was obtained, a 1-min baseline measure of cardiac coherence was obtained using a Stress Pilot biofeedback device (Biocomfort Diagnostics, Wendlingen, Germany), a soft, comfortable clip that attaches to the left earlobe. Because the impact of breathing on heart rate variability is greatest at six breaths a minute (Gevirtz \& Lehrer, 2003), the Stress Pilot device measures heart rate variability and respiration rate at a rate of six breaths. Participants were not instructed to engage in paced breathing. The device randomly selects six breaths from the breathing cycle, and then measures heart rate variability and respiration rate at a rate of these six breaths. The Stress Pilot device calculates the maximum and minimum heart rate for each breath, and then calculates the quotient of the maximum to minimum heart rate for this breath. Compared with statistical parameters (e.g., the standard deviation), this quotient is less affected by artifacts such as body movements.

Next, participants were then randomly assigned to play a violent or nonviolent game for 20 min while cardiac coherence was recorded. To increase the generalizability of findings (Wells \& Windschitl, 1999), we used three violent games (Condemned 2, Call of Duty 4, and The Club; all rated $18+$, for players at least 18-years-old) and three nonviolent games ( $S 3 \mathrm{~K}$ Superbike, Dirt 2 and Pure; all rated 10+, for players at least 10 -years-old). Before they played the game, participants were given instructions on how to play. After playing the game, participants rated how absorbing, action packed, arousing, boring, difficult, enjoyable, entertaining, exciting, frustrating, fun, involving, stimulating, and violent it was $(1=$ not at all to 7 $=$ extremely). The violent rating was used as a manipulation check. The other ratings were used as possible covariates to control for differences between video games besides violent content. Participants also listed their three favorite games. To control for habitual exposure to violent video games, we counted the number of games rated $18+$ for violent content $(0,1,2$, or 3 games), as in our previous research (Hasan, Bègue, \& Bushman, 2012; Whitaker \& Bushman, 2012). However, because the same pattern of results was obtained with and without the covariates, we used the simpler analyses that excluded the covariates.

Next, participants completed a 25-trial competitive reaction time task with an ostensible partner of the same sex in which the winner could blast the loser with loud noise through headphones. The noise levels ranged from Level $1=60$ decibels to Level $10=$ 105 decibels (about the same level as a fire alarm). A nonaggressive no-noise option (Level 0 ) was also provided. The winner could also determine the duration of the loser's suffering by controlling the noise duration (Level $1=0.5 \mathrm{sec}$ to Level $10=5 \mathrm{sec})$. The participant won 12 of the 25 trials (randomly determined). The ostensible partner set random noise intensities and durations across the 25 trials. Basically, within the ethical limits of the laboratory, participants controlled a weapon that could be used to blast their partner with unpleasant noise. This is a well-validated measure of laboratory aggression (e.g., Giancola \& Zeichner, 1995) that has been used for decades (Taylor, 1967). Finally, participants were probed for suspicion and debriefed. None of the participants expressed suspicion about the study.

\section{RESULTS}

\section{Preliminary Analyses}

Gender differences. There were no significant effects involving gender on either cardiac coherence or aggression, so the data from men and women were combined.

Exemplars of violent and nonviolent video games. No significant differences were found among the three different violent games or among the three different nonviolent games on either cardiac coherence or aggression $(P \mathrm{~s}>.05)$. Thus, the three violent games were combined and the three nonviolent games were combined for subsequent analyses.

Manipulation check of violent content of video games. As expected, violent video games were rated as more violent $(M=5.85, S D=1.44)$ than were nonviolent video games $(M=2.05, S D=1.27)$, $F(1,76)=149.45, P<.001, d=2.80$. Thus, the violent game manipulation was successful.

\section{Primary Analyses}

Cardiac coherence. Cardiac coherence was analyzed using a 2 (violent vs. nonviolent video game) $\times$ 2 (baseline vs. during game play) mixed ANOVA, with the first factor between-subjects and the second factor within-subjects. As expected, there was a significant interaction between video game content and measurement time on cardiac coherence values, $F(1,74)=$ 19.87, $P<.0001$ (see Fig. 2). Participants who played a violent game had significantly lower cardiac coherence values than did participants who had played a nonviolent video game, $F(1,75)=19.49, P<.0001 d$ $=1.02$. Cardiac coherence values at baseline did not 


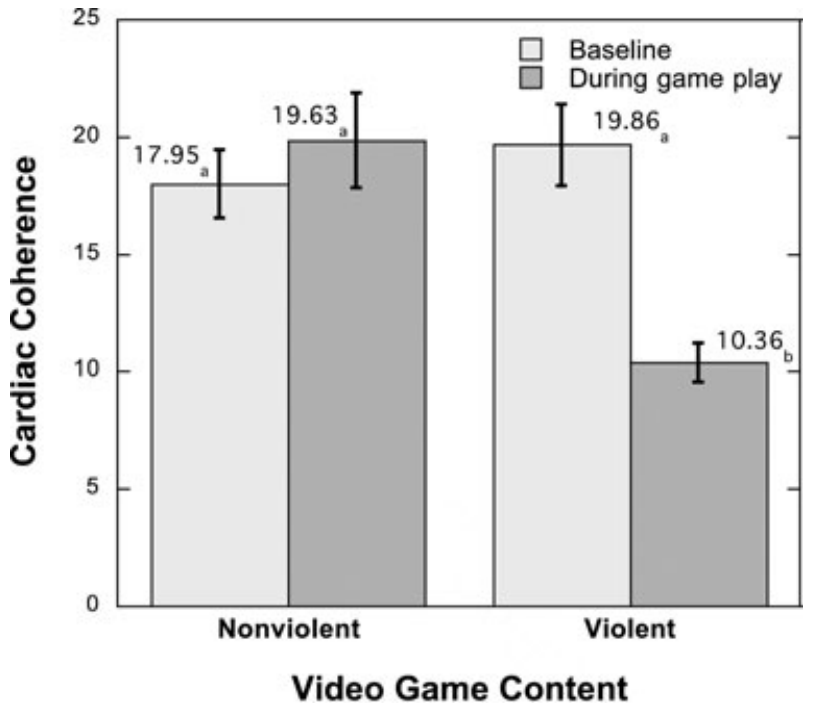

Fig. 2. Effects of violent and nonviolent video game on cardiac coherence at baseline and during game play. Means containing the same subscript are not significantly different at the .05 significance level. Capped vertical bars denote 1 standard error.

differ for participants who played violent and nonviolent games, $F(1,75)=0.53, P<.47 d=0.17$, indicating that random assignment to conditions was effective.

Aggressive behavior. As expected, noise intensity and duration levels across the 25 trials were significantly correlated $(r=.90 P<.0001)$, and were therefore averaged to form a more reliable measure of aggression. As expected, participants who played a violent game were more aggressive $(M=4.70, S D=$ $1.85)$ than were participants who played a nonviolent game $(M=3.76, S D=1.46), F(1,75)=5.99, P<.05$, $d=0.59$.

Mediation analysis. Finally, we tested whether cardiac coherence mediated the effect of playing a violent video game on aggressive behavior using bootstrap procedures (Preacher \& Hayes, 2004). As can be seen in Figure 3, the indirect effect of violent video game exposure on aggression, through cardiac coherence, was significant $(95 \% \mathrm{CI}=-0.83$ to -0.13 , which excludes the value 0 ). When both video game content and cardiac coherence were both included in the model, the effect of video game content was nonsignificant $(P>.24)$, whereas the effect of cardiac coherence was significant $(P<.03)$.

\section{DISCUSSION}

Consistent with many previous studies (see Anderson et al., 2010, for a meta-analytic review), participants who played a violent video game were significantly more aggressive afterwards than were participants who played a nonviolent video game.

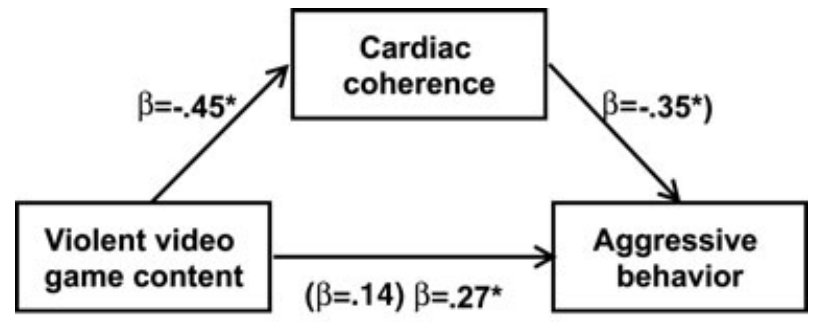

Fig. 3. Results of multiple regression analyses with game content as the independent variable $(1=$ violent, $0=$ nonviolent $)$, cardiac coherence as the mediator (time 2-time 1), and aggressive behavior (average of noise intensity and duration levels averaged across the 25 trials) as the dependent variable. The $\beta s$ in parentheses were obtained from a model that included both video game violence and cardiac coherence as predictors of aggression.

Violent game players gave their ostensible partners louder and longer noise blasts through headphones than did nonviolent game players.

The main purpose of the present research, however, was not to replicate previous findings showing that violent video games increase aggression. Our main purpose was to investigate cardiac coherence as a mediator of the link between exposure to violent video games and aggressive behavior. Our results showed that violent video games decreased cardiac coherence. Cardiac coherence, in turn, was negatively related to aggression. These findings offer one possible reason why violent game players were more aggressive. Violent games stress people out, and stressed out people tend to be cranky and aggressive.

These findings are consistent with the General Aggression Model (e.g., Anderson \& Bushman, 2002) and with cognitive-neoassociation theory (e.g., Berkowitz, 1990), which both propose that aversive emotional states increase aggression.

\section{Limitations and Future Research}

The present study, like all studies, has limitations. Although we can make causal inferences on the effects of violent video games, we cannot make causal inferences on the effects of cardiac coherence on aggression (see Bullock, Green, \& Ha, 2010). Unfortunately, it is not possible to directly manipulate cardiac coherence (Madanmohan, Prakash, \& Bhavanani, 2005). One can only manipulate factors that are expected to influence cardiac coherence, such as mood, breathing, and exercise. Second, we only measured one type of aggressive behavior (e.g., administering noise blasts to an opponent during a competitive game). Our findings may not generalize to more planned and thoughtful forms of aggression. 
Another limitation is the large percentage of females in our study. Although we found no main or interactive effects involving gender, it is difficult to conclusively test for gender differences when the number of males and females is not equal.

Another limitation is that we did not include other physiological measures such as blood pressure, heart rate, and skin conductance. It would be interesting to see how cardiac coherence compares to other physiological measures that might also mediate the effect of violent video games on aggression. Nor did we measure other possible mediators such as aggressive cognition and hostile affect. In the General Aggression Model (Anderson \& Bushman, 2002), these internal states are all interconnected. Thus, we do not know if cardiac coherence is a unique mediator of violent video game effects on aggression after controlling for other potential mediators. This remains an interesting topic for future research.

We did not measure self-reported stress because we were afraid that participants would become suspicious if we did. Thus, we can only infer based on previous research that cardiac coherence is linked to stress. However, numerous previous studies have shown that cardiac coherence is a well-accepted physiological measure of stress (e.g., Maria, 2009; Nunan et al., 2009).

\section{Conclusions}

As Natalie Golberg noted, "Stress is an ignorant state. It believes that everything is an emergency." Violent game players are placed in emergency situations in which many enemies are trying to kill them. One consequence of this exposure is an increase in stress. The present research showed that violent games reduced cardiac coherence. Cardiac coherence, in turn, was negatively associated with aggression. Thus, violent games may increase aggression in part by stressing players out. Although nobody actually gets killed in a violent game, players do experience increased stress, which makes them more cranky and prone to aggress against others.

\section{ACKNOWLEDGMENT}

We would like to thank Robert Ngueutsa for his assistance collecting data.

\section{REFERENCES}

Acharya, U. R., Joseph, P. K., Kannathal, N., Lim, C. M., \& Suri, J. S. (2006). Heart rate variability: A review. Medical and Biological Engineering and Computing, 44, 1031-1051.

Acton, Q. A. (2011). Issues in neuropsychology, neuropsychiatry, and psychophysiology. Atlanta, GA: Scholarly Editions.
Anderson, C. A., \& Bushman, B. J. (2002). Human aggression. Annual Review of Psychology, 53, 27-51.

Anderson, C. A., Shibuya, A., Ihori, N., Swing, E. L., Bushman, B. J., Sakamoto, A., ... Barlett, C. P. (2010). Violent video game effects on aggression, empathy, and prosocial behavior in Eastern and Western countries: A meta-analytic review. Psychological Bulletin, $136,151-173$.

Arriaga, P., Esteves, F., Carneiro, P., \& Monteiro, M. B. (2006). Violent computer games and their effects on state hostility and physiological arousal. Aggressive Behavior, 32, 146-158.

Barlett, C. P., \& Rodeheffer, C. (2009). Effects of realism on extended violent and nonviolent video game play on aggressive thoughts, feelings, and physiological arousal. Aggressive Behavior, 35, 213 224.

Berkowitz, L. (1990). On the formation and regulation of anger and aggression: A cognitive-neoassociationistic analysis. American Psychologist, 45, 494-403.

Berntson, G. G., Casioppo, J. T., \& Quigley, K. S. (1993). Cardiac psychophysiology and autonomic space in humans: Emirical prespective and conceptual implications. Psychological Bulletin, 114, 296-322.

Bolis, L., Licinio, J., \& Govoni, S. (2002). Handbook of the autonomic nervous system in health and disease. New York: Marcel Dekker.

Bullock, J. G., Green, D. P., \& Ha, S. E. (2010). Yes, but what's the mechanism? (Don't expect an easy answer). Journal of Personality and Social Psychology, 98, 550-558.

Bushman, B. J., \& Huesmann, L. R. (2010). Aggression. In: S. T. Fiske, D. T. Gilbert, \& G. Lindzey (Eds.), In Handbook of social psychology (pp. 833-863, 5th edn, Ch. 23). New York: John Wiley \& Sons.

Carney, R. M., \& Rich, M. W. (1988). The relationship between heart rate and heart rate variability and depression in patients with coronary artery disease. Journal of Psychosomatic Research, 32, 159164.

Chess, G. F., Tam, R. M. K., \& Calaresu, F. R. (1975). Influence of cardiac neural inputs on rhythmic variations of heart period in the cat. American Physiological Society, 228, 775-780.

Childre, D. L., \& Cryer, B. (2004). From chaos to coherence: The power to change performance. Boston, MA: Heartmath.

Church, D. (2007). The genie in your genes: Epigenetic medicine and the new biology of intention. Santa Rosa: Energy Psychology Press.

Feinstein, S. (2006). The Praeger handbook of learning and the brain. Westport, CT: Praeger.

Fourie, P. J. (2008). Media studies policy management and media representation. Cape Town: Juta.

Fraser, A. M., \& Swinney, H. L. (1986). Independent coordinates for strange attractors from mutual information. Physical Review A, 33, $1134-1140$.

Gevirtz, R. N., \& Lehrer, P. (2003). Resonant frequency heart rate biofeedback. In: M. Schwartz \& F. Andrasik (Eds.), Biofeedback: A practitioner's guide (3rd edn., pp. 245-250). New York: The Guildford Press.

Giancola, P. R., \& Zeichner, A. (1995). Construct validity of a competitive reaction- time aggression paradigm. Aggressive Behavior, 21, 199-204

Hasan, Y., Bègue, L., \& Bushman, B. J. (2012). Viewing the world through "blood-red tinted glasses": The hostile expectation bias mediates the link between violent video game exposure and aggression. Journal of Experimental Social Psychology, 48, 953-956.

Hon, E. H., \& Lee, S. T. (1965). Electronic evaluations of the fetal heart rate patterns preceding fetal death, further observations. American Journal of Obstetrics \& Gynecology, 87, 814-26.

Kahneman, D., Diener, E., \& Schwarz, N. (2003). Well-being: The foundations of hedonic psychology. New York: Russell Sage Foundation Publications. 
Kleiger, R. E., Bigger, J. T., Bosner, M. S., Chung, M. K., Cook, J. R., Rolnitzky, L. M.,... Fleiss, J. L. (1991). Stability over time of variables measuring heart rate variability in normal subjects. American Journal of Cardiology, 68, 626-630.

Lahey, B. B., Hart, E. L., Pliszka, S., Applegate, B., \& McBurnett, K. (1993). Neurophysiological correlates of conduct disorder: A rationale and a review of research. Journal of Clinical Child Psychology, $22,141-153$.

Lehrer, P. M., Woolfolk, R. L., \& Sime, W. E. (2007). Principles and practice of stress mangement. New York: Guilford.

Lynch, P. J. (1999). Hostility, type A behavior, and stress hormones at rest and after playing violent video games in teenagers. Psychosomatic Medicine, 56, 113-152.

Madanmohan, M. D., Prakash, E. S., \& Bhavanani, A. B. (2005). Correlation between short-term heart rate variability indices and heart rate blood pressure indices, pressor reactivity to isometric handgrip in healthy young male subjects. Indian Journal of Physiology and Pharmacology, 49, 132-138.

Maria, B. L. (2009). Current management in child neurology (4th ed.). Shelton: People's Medical Publishing House.

McCraty, R. (2002). Influence of cardiac afferent input on heart-brain synchronization and cognitive performance. International Journal of Psychophysiology, 45, 72-73.

McCraty, R., Atkinson, M., Tiller, W. A., Rein, G., \& Watkins, A. D. (1995). The effects of emotions on short-term power spectral analysis of heart rate variability. American Journal of Cardiology, 76, 1089-1093.

McCraty, R., \& Tomasino, D. (2006). Emotional stress, positive emotions, and psychophysiological coherence. In B. B. Arnetz \& R. Ekman (Eds.), Stress in health and disease (pp. 342-365). Weinheim, Germany: Wiley-VCH.

Mezzacappa, E., Tremblay, R., Kindlon, D., Saul, J., Arseneault, L., Seguin, J., ... . Earls, F. (1997). Anxiety, antisocial behavior, and heart rate regulation in adolescent males. Journal of Child Psychology and Psychiatry, 38, 457-469.

Mikulka, C. (2011). Peace in the heart and home: A down-to-earth guide for creating a better life. Woolwich Township, NJ: Kittacanoe press.

Miličević, G. (2005). Low to high frequency ratio of heart rate variability spectra fails to describe sympatho-vagal balance in cardiac patients. Collegium Antropologicum, 29, 295300 .

Nisbett, R., \& Wilson, T. (1977). Telling more than we can know: Verbal reports on mental processes. Psychological Review, 84(3), 231-259.

Nunan, D., Donovan, G., Jakovljevic, D. G., Hodges, L. D., Sandercock, G. R., \& Brodie, D. A. (2009). Validity and reliability of shortterm heart-rate variability from the Polar S810. Medicine and Science in Sports and Exercise, 41, 243-250.

Preacher, K. J., \& Hayes, A. F. (2004). SPSS and SAS procedures for estimating indirect effects in simple mediation models. Behavior Research Methods, Instruments, \& Computers, 36, 717-731.

Ramaekers, D., Ector, H., Aubert, A. E., Rubens, A., \& Van de Werf, F. (1998). Heart rate variability and heart rate in healthy volunteers. Is the female autonomic nervous system cardioprotective? European Heart Journal, 19, 1334-1341.

Russoniello, C. V., O'Brien, K., \& Parks, J. M. (2009). The effectiveness of casual video games in improving mood and decreasing stress. Journal of Cyber Therapy \& Rehabilitation, 1, 53-66.

Scarpa, A., \& Haden, S. C. (2006). Psychophysiological, behavioral, and emotional distinctions between childhood reactive and proactive aggression. Paper Presented at the XIX world meeting of the International Society for Research on Aggression, Minneapolis, Minnesota.

Scarpa, A., Tanaka, A., \& Haden, S. C. (2008). Biosocial bases of reactive and proactive aggression: The roles of community violence exposure and heart rate. Journal of Community Psychology, 36969 988.

Susman, E. J., \& Pajer, K. (2004). Biology behavior integration and antisocial behaavior in girls. In M. Putallaz \& K. L. Bierman (Eds.), Aggression, antisocial behavior, and violence among girls (p. 23-47). New York: Guilford Press.

Taylor, S. P. (1967). Aggressive behavior and physiological arousal as a function of provocation and the tendency to inhibit aggression. Journal of Personality, 35, 297-310.

Tiller, W. A., McCraty, R., \& Atkinson, M. (1996). Cardiac coherence: A new, noninvasive measure of autonomic nervous system order. Alternative Therapies in Health and Medicine, 2, 52-65.

Vaschillo, E., Lehrer, P., Rishe, N., \& Konstantinov, M. (2002). Heart rate variability biofeedback as a method for assessing baroreflex function: A preliminary study of resonance in the cardiovascular system. Applied Psychophysiology and Biofeedback, 27, 1-27.

Weiten, W., Dunn, D. S., \& Hammer, E. Y. (2011). Psychology applied to modern life: Adjustment in the 21st century. Belmont, CA: Wadsworth/Cengage.

Wells, G. L., \& Windschitl, P. D. (1999). Stimulus sampling and social psychological experimentation. Personality and Social Psychology Bulletin, 25, 1115-1125.

Whitaker, J. L., \& Bushman, B. J. (2012). "Remain calm. Be kind": Effects of relaxing video games on aggressive and prosocial behavior. Social Psychological and Personality Science, 3, 88-92.

Wickens, A. (2009). Introduction to Biopsychology. 3rd Edition. Harlow, UK: Pearson-Prentice Hall. 